\title{
sciendo
}

DOI: $10.2478 /$ rjp-2019-0022

Rom J Psychoanal 2019, 12(2):143-149

Rom J Psychoanal

\section{MIDLIFE - MATURITY AND CREATIVITY ${ }^{11}$}

by Valeria Egidi Morpurgo ${ }^{12,13}$

\begin{abstract}
Midlife is an age of crisis according to many authors, as it sets the subject up against the inevitability of the ageing process, loss, and the limitedness of life. Most authors view midlife as an age of crisis where everything can be staked back into the game. But some other authors have highlighted how midlife is characterised by a new burst of creativity, by new object investments and by a redressing of the balance between narcissism (which decreases) and object investments for which a larger share of the libido becomes available. The Author thinks that it seems worthwhile to make a distinction between midlife, as indicative of a phase of life, and maturity, construed as a psychic position which is relatively independent of age.
\end{abstract}

Therefore, she explores the creativity area of the trans-generational transmission, quoting some psychoanalysts and poets, and introducing a clinical example of the mourning process for losses inherent in the passing of time and the development of tolerance capacities to deal with a change in the balance between the libido and narcissism.

Then the Author affords a specific difficulty in transmitting a trans-generational mandate, when the treatment concerns cases of severe trauma, like victims of collective

\footnotetext{
${ }^{11}$ AN EXCERPT: the Author uses the poetry to illustrate her view of maturity: the time when one integrates what has gone before into a form of wisdom that will be valued in the future by the individual and future generations.

${ }^{12}$ Italian Psychoanalytical Society; angela.manganaro@yahoo.it

${ }^{13}$ RJP thanks to Anna Ferruta and Angela Manganaro for their help to edit this paper
} 
trauma and mass murders. What can be transmitted in these cases if the psychological concatenation between the generations is interrupted and breaks down? How can it be linked up again? The story and re-elaboration by Henri Parens is brought as an example to be studied and commented.

Key words: midlife, maturity, transgenerational mandate, transmission, trauma, elaboration

\section{Maturity and creativity}

Maturity is not necessary age-related. It may be viewed as a psychological standpoint that can present or re-present itself several times over the lifespan.

Creativity, too, can present itself in various forms and moments during the course of human existence when understood in its wider sense of a capacity to bring thought, or a new and original project, to light in any branch of knowledge or of life.

What is the origin of creativity, according to psychoanalysis? Is there a 'mature' creativity, distinct from a 'juvenile' form of creativity? And if this is the case, can we detect an awareness of the ability, or responsibility, to receive and pass on a legacy of knowledge across generations in this mature manifestation?

Several psychoanalytic theories of maturity have been proposed, but such a vast corpus of literature can scarcely be reviewed here. I shall have to limit myself to observe with Freud that wecould think of creativity as the derivative of the working through of an absence, which posits that the genesis of thought is in the working through of grieving, as Freud's story of the fort/da child's game shows.

However, the energy aspect is never wholly absent from Freud's thinking, that is to say, there is never any lack of reference to the libido and libidinal investments in objects. For Freud, mourning is "normally" terminated with the libido re-investing in the external world and objects. Thus, Freud accounts for some aspects of the force and intensity of investments which become particularly useful when thinking about artistic creativity and its trials.

Hanna Segal aligned herself with Freud on a similar stance (1991). She thought creativity was linked to our capacity for reparation. In other words, Segal thought that the work of the 
artist is to search for reparation in the face of the human capacity for destruction, which means addressing schizo-paranoid and depressive anxieties while accepting losses and separation.

From these theoretical considerations, one thing appeals to me as a particularly valid hypothesis: that the artist's psychic work is actually reproduced in the recipient of the work of art, albeit in a partial and attenuated form. Thus, the recipient of art (who could be a reader, a spectator or a visitor) obtains a benefit from the work of art that can be worked through this individual's anxieties.

This harks back to a theory of great antiquity, the Aristotelian doctrine of catharsis, or the purification of the passions in the spectator of tragic drama. This is given new life on psychoanalytic principles. Aesthetic consumption becomes an evolutionary stage: if not exactly therapeutic, it at least allows a re-integration of parts of the self.

While working on overcoming mourning, Ilany Kogan in The Struggle Against Mourning (2007) explored creativity as a form of resilience that lets us surmount severe trauma and, in a sense, work it through, from the recognition of projective identifications and pathological contents deposited within the unconscious of descendants of collective trauma victims.

I will not pursue here this fascinating topic, the difference between young artists and mature ones, who are 'mature' in the sense that they are now middle-aged. This is a theme that Elliott Jaques has dealt with and which, as is well known, is what Dante Alighieri's "Nel mezzo del cammin di nostra vita" (Inferno, Canto I, verse 1) refers to, the life crisis of the thirty-fifthyear.

There is evidence to support the hypothesis that artistic maturity is comparatively unconnected with chronological age and this holds true whether we regard maturity as a formal capacity, which is special and specific, depending on the author's creative or artistic field of action, or if we review maturity from the standpoint of the contents that are expressed - if we agree with the traditional division between form and contents in aesthetic theory.

Many examples could be mentioned in support of this thesis. It will suffice to recall two poets who understood how to evoke the absolute in their writings despite their young age. Leopardi was 21 when he composed his sonnet, L'infinito, which is a poignant meditation on the feeling of communion with the universe, a sentiment which Freud, a century later, would describe as oceanic. Emily Dickinson was 28 when she wrote in a short poem: 
"It's all I have to bring today -

This and my heart besides - ..."

(The Complete Poems, no. 26, p. 18)

From another point of view, it cannot be denied that artists evolve during their career and transform both the form and contents of their work. Jaques' research identified the change of approach to new themes among literary artists as a form of reconciliation with the limitations of life following their thirty-fifth-year crisis.

In painting and sculpture, especially among artists in the past, these formal changes crop up with regularity. Following a juvenile phase of apprenticeship and membership of a school of likeminded artists during which the influence of a master can be felt, transition steps full of conflicts and turbulence can be discerned while artists develop their own independent forms and themes.

\section{Psychic maturity and trans-generational transmission}

Horace ( $65 \mathrm{BC}-8 \mathrm{AD})$ was the leading poet of the Augustan age and culture. His creativity was sustained by a seemingly inexhaustible capacity for new investments. This was the basis of his capacity to address limitations and losses. He affords us a glimpse of the parallel processes of psychic and artistic maturity as few other poets have done. Both forms of maturity are linked to Horace's awareness of the importance of his intergenerational legacy and to his passionate commitment to its transmission.

\section{Exegi monumentum aere perennius}

regalique situ pyramidum altius

quod non imber edax, non Aquilo inpotens

possit diruere aut innumerabilis

annorum series et fuga temporum.

Non omnis moriar multaque pars mei

Vitabit Libitinam...

ex humili potens,

princeps Aeolium carmen ad Italos

deduxisse modos.

(Carminum, Liber III, 30) 
I have completed a monument more lasting than bronze

and higher than the decaying Pyramids of kings,

which cannot be destroyed by gnawing rain

nor wild north wind, or by the unnumbered

procession of the years and flight of time.

I shall not wholly die. A great part of me

will avoid Libitina.

ruled the country peoples,

it will be said of me that from humble beginnings

I had the power to be the first to bring Aeolian song

to Italian measures.

(David West, p. 259)

The first three books of the Odes were composed between 30 and $23 \mathrm{BC}$ and Horace may have died around his fifty-seventh year. In this ode, published when the poet was about forty years old, Horace moves away from the thought of human transience while allowing us to see his self-confidence and pride in his poetic artistry.

Is this narcissistic ostentation? It could be, but what a healthy sort of narcissism it must have been, if we are still reading Horace and admiring his work two millennia later!

This suggests that the poet was not unjustly convinced of his capacities of communication, of making himself able to speak to us beyond his time, and, first and foremost, to be able to hand down to us a legacy of thought, an inheritance that still enriches our lives, the lives of his posteri, today! Horace's verses still teach us that one may outrace the fuga temporum through the medium of art.

It may also be, as Heinz Kohut (1992) remarked, that this is a case of creative processes inducing a transformation of narcissism (p. 97). The poet is aware of the finiteness of his life, but he also knows that his legacy is not of a material nature. Horace insists on these themes in the first lines of the ode which document that a sort of clash occurred between thoughts of destruction and death (represented by devastating rains, the raging wind, the relentless passing of time and by Libitina, goddess of funerals) and his own resistance against dissolution, or resilience, as we would perhaps say today. What Horace displays here is his trust in a life beyond the succession of centuries as something that his poetic artistry makes possible for him. 
And he explicitly tells us:

Non omnis moriar

I shall not die whole

(Odes, III.30.6)

Horace does not go into denial, therefore, nor does he deny mortality as his fate; on the contrary, he faces it heads on, gives it a name, even if he grammatically uses the negative.

And he throws down the gauntlet at us: his art will afford him not to die entirely, but a great part of (him) shall live on. To which we may add, he will live on in other people's minds.

This ode is an extraordinary instance of a mature reflection, as it is also the sign of successful mourning for parts of the self. The poet even uses the very words "parts of (him)self": multaque pars mei, or "a large part of me".

All this is connected with the theme of trans-generational transmission, and works both ways, as he looks back to his predecessors, the patres, or venerated models, and at the same time he is looking forward to a symbolic descendancy. Horace is turning to his masters, the Greek poets, and he is proud to have them as his own legacy, to have become their equal in their art. But he is also speaking to his readers, his contemporaries and his descendants. He is proud of having handed down to them this prestigious legacy in a personal form, writing poetry in Latin, his own tongue, and on Italian soil. 


\section{REFERENCES}

DANTE, A. (1555). La Divina Commedia. Inferno. Mondadori, Milano, 2016.

DICKINSON, E. (1955). The Complete Poems. Faber\&Faber, London, 1976.

JAQUES, E. (1993). L'età di mezzo. Scritti di E. Jaques, O. F. Kernberg, C. M. Thompson. Bollati Boringhieri, Torino. [The Midlife. Writings]

LEOPARDI, G. (1819). L'infinito. In “Canti” (1835). Feltrinelli, Milano. [The Infinity]

KOGAN, I. (2007). The Struggle Against Mourning. Jason Aronson Inc, Lanham, Maryland (USA).

KOHUT, H. (1992). The Search for the Self. University of Chicago Press, Chicago, 2009.

WEST, D. (1995). Horace Odes. Clarendon Press, Oxford. 